\title{
ENSINO DE LÍNGUA PORTUGUESA: O PAPEL DOS JOGOS DE INTER(AÇÃO)
}

\section{PORTUGUESE LANGUAGE TEACHING AND INTERACTION: THE ROLE OF THE GAMES}

Ana Luisa Feiteiro Cavalari*

\begin{abstract}
Resumo: Neste artigo, busco apresentar os Jogos de Interação como uma possibilidade metodológica para o ensino de Língua Portuguesa no Ensino Fundamental II. Os Jogos, amplamente difundidos no meio teatral, constituem importante contribuição para a vivência e a experiência com e por meio da linguagem. A fundamentação teórica centrase na Psicologia, na Linguística e na Pedagogia do Teatro, sobretudo na perspectiva da "Linguagem Interacional" como constitutiva dos sujeitos bem como na visão não-dualista de corpo e mente.
\end{abstract}

Palavras chave: Ensino de Língua Portuguesa; interação; linguística; jogos.

\section{Introdução}

O teatro é uma arte interacional por excelência, foi nele, portanto, que busquei inspiração para a apresentação de uma proposta metodológica para o ensino de Língua Portuguesa que se baseia em dois princípios fundamentais; a linguagem

* Atriz formada pelo Teatro Escola Macunaíma e mestranda do Programa de Pós-Graduação em Língua Portuguesa da Universidade de São Paulo - USP 
CAVALARI, A. L. F. Ensino de língua portuguesa...

como interação, como forma de ação e de aprender com e por meio do outro; e a vivência da linguagem para internalizá-la, apreendê-la, aprendê-la e experienciá-la.

Os Parâmetros Curriculares Nacionais (PCN) de Língua Portuguesa destacam que "a atividade mais importante" dos professores "é a de criar situações em que os alunos possam operar sobre a própria linguagem". Para tanto, utilizei como base os jogos do teatro em três vertentes, a saber: os jogos de Augusto Boal do Teatro do Oprimido, o Jogo Teatral de Viola Spolin e os Jogos Dramáticos de Jean-Pierre Ryngaert.

Nos Estados Unidos, Canadá e França os jogos são amplamente difundidos no meio escolar, no Brasil, no entanto, são utilizados apenas como metodologia para ensino de língua estrangeira, principalmente inglesa e francesa, dada a amplitude de sua aplicação naqueles países. Não obstante, foram também difundidos no Brasil, sobretudo nas décadas de 1980 e 1990, por estudiosos da "Pedagogia do Teatro".

Com uma abordagem nova que enfoca o ensino-aprendizagem de Língua Portuguesa no Ensino Fundamental II, apresento os Jogos de Interação, termo por mim cunhado e desenvolvido, como uma possibilidade metodológica a ser trabalhada nesta disciplina.

\section{Linguagem, inter(ação) e a constituição dos sujeitos}

Autores de diferentes áreas do conhecimento como Psicologia, Filosofia e Linguística destacam que é através da interação realizada por meio da linguagem que nos constituímos como sujeitos e nos localizamos no mundo, que tomamos consciência de nós mesmos e dos outros; esta consciência é "experimentada por contraste", pois, não é possível o emprego de um "eu”, sem a distinção de um "tu". Neste sentido, para Benveniste (1995) "essa condição de diálogo é que é constitutiva da pessoa, pois implica em reciprocidade - que eu me torne "tu" na alocução daquele que por sua vez se designa por "eu"”.

Ainda de acordo com esse autor "a linguagem está na natureza do homem que não a fabricou". Assim, Benveniste (1995) discorre que é inconcebível o homem dissociado da linguagem da mesma forma que não é possível verificar o homem inventando-a, igualmente é inconcebível compreender o homem reduzido a si, sem a concepção de um outro. É através da fala, da interação, que os localizamos no mundo, e é a linguagem que nos fornece a própria definição de homem. Ainda 
em consonância com o autor e aprofundando a discussão acerca da relação entre pensamento e linguagem, é através desta e por seu intermédio que o homem se constitui como sujeito.

A distinção dialógica que constitui o ser de acordo com os estudos de Benveniste (op.cit.) constitui a linguagem e torna-se ponto central da teoria de Bakhtin (1992) [1929]. Estudiosos, como Barros (2001), entendem que o conceito de dialogismo deva preceder à preocupação em torno do texto e do discurso. Para Bakhtin 1992 [1929] o dialogismo é o princípio que constitui a linguagem e o sentido do discurso; desdobra-se em dois aspectos: a interação verbal que ocorre entre o enunciador de um texto e seu enunciatário, e a intertextualidade encontrada no interior do discurso.

Acerca da interação verbal, o autor discorre que este conceito organiza a enunciação, ocorre exteriormente e situa-se no meio social Bakhtin (opt. Cit). Portanto, a enunciação é resultado da interação social. Pode ocorrer tanto na fala em uma situação imediata, como em um contexto geral construído no interior de uma comunidade linguística. Desta forma, a interação verbal constitui "a realidade fundamental da língua" Bakhtin (opt. Cit).

Explica-se a intertextualidade como as muitas vozes que estão contidas no discurso, os muitos textos que constituem cada texto, ou seja, um texto, ou discurso, traz marcas de outro texto ou discurso; isto significa dizer que na voz de um enunciador, as vozes de outros enunciadores ecoam.

O conceito de dialogismo, embora não definido como tal por Vygotsky (2003) também permeia seus escritos. A esse respeito, Smolka (1991) enfatiza que o dialogismo de Bakhtin é uma complementação e uma ampliação dos princípios apresentados por Vygotsky. Smolka (1991) afirma que, para Vygotsky, provém do social todas as funções mentais que são específicas do homem, o autor prioriza e enfatiza tanto a mediação como as origens sociais do funcionamento mental como os princípios capazes de explicar o processo de formação histórica da consciência. Emerson $(1983)^{1}$ destaca outro ponto comum entre as teorias de Vygotsky e Bakhtin,

1 "Vygotsky's distrust of the classic psychological experiment (what he derisively called the "stimulus-response framework") should in fact recall Bakhtin's distrust of the classic linguistic model, with its ideal speaker and ideal (or nonexistent) listener. Both were suspicious of modeling, for both insisted that only the concrete historical event could validate a human communication or lead to an act of learning".

A desconfiança de Vygotsky do modelo clássico da psicologia experimental (estímulo pergunta-resposta) deveria na verdade remeter a desconfiança de Bakhtin do modelo 
CAVALARI, A. L. F. Ensino de língua portuguesa...

os autores "acreditavam que apenas fatos históricos concretos poderiam validar uma comunicação humana ou levar ao ato de aprender". Os estudiosos chegaram a estas conclusões discordando de modelos preestabelecidos em suas áreas de conhecimento. Vygotsky duvidando do modelo "estímulo pergunta-resposta" e Bakhtin, duvidando do modelo do "falante ideal" e do "ouvinte ideal (inexistente)". Cumpre apontar que a inter-relação existente entre estas ciências deriva das interrelações existentes entre os próprios objetos de seus estudos.

Para Vygotsky (2003), a linguagem “essa estrutura humana complexa” deriva "de um processo de desenvolvimento profundamente enraizado nas ligações entre história individual e história social" Ainda de acordo com Vygotsky (op. cit), as palavras e os signos constituem o primeiro meio de contato social do homem. São as funções cognitivas e comunicativas da linguagem que distinguem o homem dos animais.

A distinção entre o homem e os animais também foi tratada por Luria (1991), para o autor a transição que ocorreu da história natural dos animais para a história social do homem só foi possível devido a dois fatores: o surgimento da linguagem, e o emprego dos instrumentos de trabalho e o trabalho social. Por conseguinte, a "linguagem teve importância decisiva para a posterior reorganização da atividade consciente do homem" (Luria 1991). Ainda segundo o autor, a linguagem tem a propriedade de duplicar o mundo perceptível, possibilita a conservação da informação recebida do mundo exterior e permite a criação de um mundo de imagens interiores. É por meio dela que somos capazes de "dominar um ciclo imensurável de conhecimentos, habilidades e modos de comportamento, que em hipótese alguma poderiam ser resultado da atividade independente de um indivíduo isolado" (Luria 1991). Neste excerto, parece haver uma confluência entre os conceitos deste autor e os apresentados por Vygotsky, mais amplamente desenvolvidos por Bakhtin, tanto acerca da interação verbal como o conceito de dialogismo que, para Bakhtin, perpassa a linguagem e marca suas idéias sobre o próprio homem.

linguístico clássico do falante ideal e do ouvinte ideal (inexistente). Ambos suspeitavam dos modelos, pois insistiam que apenas fatos históricos concretos poderiam validar uma comunicação humana ou levar ao ato de aprender. (tradução própria). 


\section{Contribuições da Linguística Cognitiva}

Para a área de estudos denominada "Linguística Cognitiva" a divisão entre corpo e mente não existe. Esta visão, não dualista, entende que não havendo uma separação entre o que seria uma "mente" e o que seria um "corpo", a linguagem não poderia ser entendida como pertencente a "mente". Nesta perspectiva teórica, a experiência constitui-se não como algo do corpo, tampouco da mente, mas como proveniente do não-dualismo, da não separação entre corpo e mente. Dewey Apud Koudela (2001):

A natureza da experiência inclui um elemento ativo e um passivo. A parte ativa significa que experiência é experimentar (trying) e a passiva é experenciar (undergoing). Quando experimentamos alguma coisa agimos sobre ela e depois sofremos as consequências. É a conexão entre estas duas fases da experiência que dá a medida de seu sucesso ou valor. Mera atividade não é experiência, pois ela envolve uma mudança. E essa mudança só pode se processar quando a atividade é conscientemente relacionada com as consequências que provêm dela.

Como exemplo, a autora descreve uma situação em que uma criança pequena queima seu dedo, esta criança ao sofrer a consequência deste ato, ou seja, a dor ocasionada pela ferida tornará o fato uma experiência. Por conseguinte, para Koudela (op.cit) "aprender por meio da experiência significa o estabelecimento de um relacionamento entre antes e depois, entre aquilo que fazemos com a coisa e aquilo que sofremos como consequência". Koudela (op.cit) enfatiza que este conceito não se aplica à arte visto que, "o desligamento da sua realidade é um fator indicativo de sua natureza". Embora este conceito não se aplique à educação artística, aplica-se ao ensino da língua na medida em que podemos "experienciar" a linguagem. Nesta perspectiva, a experiência não é algo da "mente" exclusivamente.

De acordo com Dewey Apud Johnson (2006), "mente" é uma propriedade, uma capacidade que uma criatura que sente assume quando chega a uma organização interacional com outras criaturas vivas por meio da linguagem, da comunicação.

Johnson (2006) no artigo Mind incarnate: from Dewey to Damasio, destaca essencialmente sete implicações da proposta não-dualista, a saber: 1- "não existe mente sem corpo"; 2- " a mente não é uma "coisa"; 3- "o corpo na mente e a mente no corpo"; 4- "a lógica é matéria do corpo"; 5- "a língua e os símbolos interacionais são matérias do corpo"; 6- "o corpo é mais do que matéria”, e, 7- "os valores são corporeados”. Apresento a seguir cada uma dessas implicações: 
CAVALARI, A. L. F. Ensino de língua portuguesa...

1- "Não existe mente sem corpo": a doutrina da cognição corporeada é uma perspectiva que se fundamenta em experiências, pensamentos, valores e ações de uma consciência fortemente corporeada que aparece como uma pequena parte do extenso e contínuo processo evolucionário.

2- "A mente não é uma "coisa": embora nasçamos com as capacidades cognitivas necessárias para as experiências e os pensamentos humanos, é um equívoco dizer que nascemos com uma "mente" entendida como entidade dada. Para "ter uma mente" é necessário que nosso nível de capacidade enquanto seres racionais se eleve e passe a sustentar conjuntos complexos de funções que envolvem decisões, pensamentos, sentimentos e comunicação com os outros. Portanto, ter uma mente significa ser capaz de sustentar um grupo complexo de funções e processos dinâmicos, e não dizer que temos uma estrutura como se mente fosse uma entidade.

3- "O corpo na mente e a mente no corpo": o corpo não é um mero assento da mente ou um lugar em que ela descorporeada repousa. O corpo e a mente são diferentes aspectos do processo interacional da experiência em curso. Assim, a natureza de nossos corpos humanos determina o que nós podemos experienciar e pensar; e, também, como nós pensamos, ou seja, como nós conceituamos e raciocinamos. O corpo está na mente, da mesma forma que a mente está no corpo.

4- "A lógica é matéria do corpo": tradicionalmente, a lógica tem sido entendida como pura (sem interferência do corpo), universal e absoluta, como a essência do pensamento racional, ou seja, transcendendo o corpo. Mas se o corpo é constitutivo do que e de como nós pensamos, então a lógica depende do corpo tanto quanto os outros processos cognitivos.

5- “A língua e os símbolos interacionais são matérias do corpo": a Linguística Cognitiva procura explicar a linguagem como resultado de capacidades cognitivas gerais ativas mais do que como resultado de módulos linguísticos autônomos. Além disso, as abordagens corporeadas para a linguística cognitiva apresentam evidências empíricas de que os padrões e os processos de experiência sensório-motora constituem a base dos significados linguísticos e de outras formas de interações simbólicas. Tais evidências incluem análises de como as palavras que nós usamos para falar sobre a mente e os processos mentais são definidos de acordo com modelos cognitivos baseados em estruturas sensório-motoras, ou ainda, em um sistema conceitual de metáforas com base indiretamente em aspectos da experiência sensório-motora. 
6- "O corpo é mais do que matéria": assim como a mente não pode ser reduzida ao cérebro, o corpo não pode ser considerado uma matéria feita de pele e ossos. Há várias formas de ver o corpo: primeiro, há o corpo como organismo fisiológico composto de matéria, ossos, pele, músculos, nervos e os vários órgãos de percepção e manutenção da vida, todos organizados em um sistema interativo complexo; há também, o corpo em que o cérebro e o sistema nervoso central nos permitem experienciar, monitorar e modificar durante nossas interações com o ambiente; e finalmente, há também o corpo que não se limita à nossa pele, mas que se estende no ambiente, de forma que o organismo e o ambiente não são independentes, mas sim, aspectos interdependentes do fluxo de experiência corporeada.

7- "Os valores são corporeados": a visão naturalista de mente entende que os valores emergem das necessidades dos organismos de sobreviver, crescer, florescer, e, para os humanos, encontrar significado dentro do ambiente em que vivem. Os ambientes são físicos, sociais, culturais, morais, econômicos, políticos, espirituais, e possuem gêneros e raças. Portanto, muitos dos nossos valores são resultados diretos dos instintos de sobrevivência dos nossos corpos e outros são consequências da nossa natureza como seres políticos e sociais.

A partir dessas considerações acredito que um ensino de língua que tenha como compromisso embasar-se na interação e na experiência com e por meio da linguagem, não pode comprometer-se com a visão dualista de separação entre corpo e mente restringindo a linguagem a este segundo "compartimento".

\section{Arte, inter(ação) e jogo}

A ação e o diálogo são inerentes às manifestações artísticas de qualquer natureza. Arte é discurso e como discurso é dialógica. Neste sentido, o agir ou o inter(agir) é também um fazer artístico, uma ação artística, e, por que não dizer, linguística. A inter(ação) pressupõe uma ação. A arte se dá, sobretudo, não apenas no produto final, ou seja, na obra de arte, mas na relação entre a obra e seu público e entre o artista e o outro.

Um episódio célebre serve para embasar as discussões acerca da arte como interação. Uma feminista britânica esfaqueou o quadro do pintor Velásquez Vênus ao Espelho em 1914, sob a alegação de que as mulheres não estavam presentes nos museus, salvo como objeto, retratadas nuas nas telas dos pintores. Uma questão 
CAVALARI, A. L. F. Ensino de língua portuguesa...

coloca-se, então, para os estudiosos deste campo de pesquisa: a arte não é também, ou é apenas, o que a obra de arte pode sussitar no outro? $\mathrm{O}$ ato da sufragista, para muitos autores, demosntra que é na relação social que a arte ganha seu sentido completo.

No Brasil, na década de 1960, as artes plásticas inauguram um movimento tendo como maior expoente Lygia Clark que propõe a ruptura da obra de arte e uma nova visão acerca da arte e do artista. Para Lygia Clark a arte se realiza na relação entre a obra e os sujeitos (os receptores). Nas palavras da artista:

Somos os propositores; somos o molde; a vocês cabe o sopro, no interior desse molde: o sentido da nossa existência. Somos os propositores: nossa proposição é o diálogo. Sós, não existimos; estamos a vosso dispor. Somos os propositores: enterramos a obra de arte como tal e solicitamos a vocês para que o pensamento viva pela ação. Somos os propositores: não lhes propomos nem o passado nem o futuro, mas o agora. (Clark, 1968)

O conceito do dialogismo de Bakhtin 1992 [1929] no tocante à interação verbal que ocorre entre o enunciador de um texto e seu enunciatário aplica-se, também, às dimensões artísticas da língua, a literatura e a poesia. Desta forma, a literatura e a poesia são, nesta perspectiva, arte interacional.

Uma forma de inter(ação) que pode ser artística ou não, bastante difundida, principalmente no contexto escolar, são os jogos. Existe um tipo específico de jogo, o que aqui denominei jogos de interação, que é um jogo, mas ao mesmo tempo um fazer artístico. Os jogos no teatro foram inicialmente desenvolvidos para o treinamento de atores e, no campo da licenciatura em Artes Cênicas e nos meios teatrais, são amplamente difundidos em todo o mundo.

Os Jogos do Teatro chegaram ao Brasil por meio de três vertentes principais, a saber: os jogos de Augusto Boal, o Jogo Teatral de Viola Spolin e os Jogos Dramáticos de Jean-Pierre Ryngaert.

Augusto Boal, diretor e teórico de teatro, desenvolveu com base, inicialmente, nas teorias de Bertolt Brecht, uma série de exercícios ("monólogos corporais") e jogos ("diálogos corporais") transformados em um método designado Teatro do Oprimido. Nas palavras do teatrólogo "O Teatro do Oprimido é teatro na acepção mais arcaica da palavra: todos os seres humanos são atores, porque agem, e espectadores, porque observam. Somos todos "spect-atores". O Teatro do Oprimido é uma forma de teatro, entre tantas outras". (Boal, 2002). 
O livro Jogos para atores e não-atores possui doze edições em inglês, quinze em francês, traduções em português europeu e diversas outras línguas nos cinco continentes. Inicialmente, foi publicado em Espanhol, na Argentina, em 1973, quando Boal encontrava-se no exílio. Apesar de Boal ser brasileiro, o método foi aplicado primeiro na América Latina e Europa, para posteriormente chegar ao Brasil.

Sartingen (1998) destaca que "para compreender corretamente essa poética do oprimido, é preciso ter diante dos olhos seu objetivo principal, transformar o povo, o espectador, o elemento passivo do teatro em sujeito, em ator, em transformador da ação dramática".

Os Jogos Teatrais são um método desenvolvido por Viola Spolin, diretora de teatro norte-americana, com o intuito de utilizá-lo na preparação de atores, no ensino de teatro para iniciantes, bem como, no contexto escolar.

A especialista sistematizou suas experiências obtidas por meio da, entre outras, atuação junto a instituições voltadas à integração de crianças em vulnerabilidade social e filhos de imigrantes, nos Estados Unidos, e inseriu o sistema no meio escolar. Seus trabalhos exerceram influência profunda, na década de 1960, no teatro de vanguarda norte-americano.

As teorias de Spolin repercutiram amplamente no meio educacional brasileiro, sobretudo, na década de 1980, após a experimentação desta metodologia pelo grupo de pesquisadores em Teatro e Educação da Escola de Comunicação e Artes (ECA) da USP, liderado por Ingrid Dormien Koudela, quem primeiro traduziu a obra Improvisação para o teatro, de Viola Spolin para o Português, lançada em 1979.

Com esta abordagem, a dos Jogos Teatrais, destaca Belinky, no prefácio da obra Jogos Teatrais, Koudela, defendeu em 1982, a dissertação de mestrado Jogos teatrais, um processo de criação. Nesse trabalho "a autora defendeu a linha "essencialista" da Arte-Educação, demonstrando que o valor educacional da arte reside na sua natureza intrínseca, sem precisar de outras justificativas", e, aponta para, "a potencialidade do teatro no desenvolvimento intelectual, social e afetivo da criança".

Os Jogos Dramáticos de Jean-Pierre Ryngaert surgiram na França com Jacques Copeau (1879-1949), fundador do Vieux Colombier, Charles Dullin (18851949), criador do Atelier e Léon Chancerel (1886-1965), autor que cunha o termo em 1930. Tais considerações são tecidas por Maria Lúcia de Souza Barros Pupo, no 
CAVALARI, A. L. F. Ensino de língua portuguesa...

prefácio intitulado Para uma Pedagogia do Teatro à obra Jogar, representar Práticas dramáticas e formação de Ryngaert.

Pupo salienta que em seu primeiro livro O Jogo Dramático no Meio escolar Ryngaert "discute criticamente princípios valiosos para a elaboração de uma pedagogia para o teatro. Assim o Jogo Dramático dá um salto importante no contexto francês". Em Jogar, representar - Práticas dramáticas e formação Ryngaert, ainda em consonância com Pupo, o jogo promove a primeiro plano "as relações entre o sujeito e o jogo e os signos de teatralidade organicamente engendrada". É, portanto, esta perspectiva de jogo que me interessa no tocante às aulas de Língua Portuguesa e as concepções de linguagem por este artigo tratadas.

Cunhei o termo Jogos de Interação (inter, diálogo e agir/ação, acepção primeira da palavra teatro) para denominar os jogos destinados ao ensino de Língua Portuguesa. Tais jogos têm suas raízes nos Jogos Teatrais de Viola Spolin, nos Jogos Dramáticos de Ryngaert e nos jogos do Teatro do Oprimido de Boal. O que o diferencia dos demais é a finalidade. O Jogo de Interação é, portanto, o jogo que se destina ao ensino de Língua Portuguesa para as escolas do Brasil no século XXI.

\section{Os jogos de interação como contribuição na formação dos sujeitos e desenvolvimento das linguagens nas aulas de Língua Portuguesa}

Para melhor elucidar como os jogos podem contribuir de maneira fundante no ensino fundamental II, recorro ao PCN de Língua Portuguesa:

O domínio da linguagem, como atividade discursiva e cognitiva, e o domínio da língua, como sistema simbólico utilizado por uma comunidade linguística, são condições de possibilidade de plena participação social. [...] O objeto de ensino e, portanto, de aprendizagem é o conhecimento linguístico e discursivo com o qual o sujeito opera ao participar das práticas sociais mediadas pela linguagem. [...] Ao professor cabe planejar, implementar e dirigir as atividades didáticas, com o objetivo de desencadear, apoiar e orientar o esforço de ação e reflexão do aluno, procurando garantir aprendizagem efetiva. [...] A atividade mais importante, pois, é a de criar situações em que os alunos possam operar sobre a própria linguagem, construindo pouco a pouco, no curso dos vários anos de escolaridade, paradigmas próprios da fala de sua comunidade, colocando atenção sobre similaridades, regularidades e diferenças de formas e de usos linguísticos, levantando hipóteses sobre as condições contextuais e estruturais em que se dão. 
Acredito que o jogo pode ser uma maneira de, como tratam os PCN, "criar situações em que os alunos possam operar sobre a própria linguagem", sendo esta, a "atividade mais importante" do professor de Língua Portuguesa.

À luz das teorias acerca da linguagem tratadas neste artigo, sobretudo seu caráter interacional como constituinte dos sujeitos, e, a quinta implicação apresentada por Johnson (op.cit) da proposta não-dualista, "a língua e os símbolos interacionais são matérias do corpo" e a experiência "quando o fazer torna-se experimentar", de Koudela (2001), afirmo o caráter imprescindível do jogo nas aulas de Português. Ademais, existe outro aspecto, não menos importante, que justifica a presença dos jogos nas aulas; a estreita relação que estes possuem com as artes.

Entendo arte como linguagem, como discurso. Entendo a interação, como "a realidade fundamental da língua" (Bakhtin 1992 [1929]). Portanto, claro está, que a arte também é dialógica por ser parte da linguagem, e formadora dos sujeitos, que, apenas constituem-se na interação, na relação com o outro, no jogo com o outro. Neste sentido, os jogos cumprem uma função primordial no ensino de Língua Portuguesa, o de introduzir ao mesmo tempo a interação, a arte e a vivência (experiência) da linguagem.

Nesta perspectiva, interessa-me, portanto, o caráter da interação, da "experienciação" e da constituição dos sujeitos inerentes aos jogos e essenciais ao ensino de qualquer língua, não apenas o Português. Sobretudo, interessa-me, o desenvolvimento das linguagens nas crianças e nos adolescente.

Outro aspecto que acredito ser importante para esta discussão relaciona-se ao trabalho com as manifestações artísticas da língua; a literatura e a poesia. $\mathrm{O}$ ensino de tais manifestações faz parte do currículo de Língua Portuguesa, e, formar sujeitos capazes de compreender, interagir e apreciar a dimensão artística destas manifestações deve ser também uma das atribuições do professor desta disciplina. Contudo, como formar leitores, apreciadores da literatura, amantes da arte, sujeitos artísticos sem ensinar arte também nas aulas de Língua Portuguesa? Mais uma vez, parece-me que o jogo e seu caráter artístico constituem-se importantes ferramentas para este trabalho em sala de aula.

Para Jean-Pierre Ryngaert (2009) "o jogo facilita uma espécie de experimentação sem riscos do real, na qual a criança se envolve profundamente". Viola Spolin (2010) afirma que "os jogos teatrais vão além do aprendizado teatral de habilidades e atitudes, eles são extremamente úteis em todos os aspectos da aprendizagem e da 
CAVALARI, A. L. F. Ensino de língua portuguesa...

vida". De acordo com Ricardo Japiassu (2009) "o crescimento pessoal e o desenvolvimento cultural dos jogadores" pode ser obtido "por meio do domínio, da comunicação e do uso interativo da linguagem teatral, numa perspectiva improvisada ou lúdica". Olga Reverbel (2007) afirma que "se o aluno desenvolver suas capacidades de expressão, ou seja, espontaneidade, percepção, observação, imaginação e relacionamento grupal, estará aberto para todo tipo de aprendizagem". $\mathrm{O}$ jogador é aquele que "experimenta", a si, aos outros e a linguagem.

Os jogos revelam, sobretudo, a apropriação pelos alunos de um aspecto precioso para o entendimento do fazer teatral: a interação entre os jogadores e os jogadores e a interação entre os jogadores e o público. Esse envolvimento é primordial para o aperfeiçoamento da comunicação global do aluno, e, consequentemente, da linguagem.

\section{Uma proposta de sequência didática para aplicar os Jogos de Interação nas aulas de Língua Portuguesa.}

Antes de proceder às explicações concernentes ao jogo, acredito ser necessário destacar alguns aspectos relativos a essa prática pedagógica, a saber: 1o jogo não é só brincadeira; 2- jogar não significa não preparar a aula, nem "matar o tempo"; 3- após jogar, é necessário refletir; 4- não adianta jogar apenas uma vez; 5- jogar não é expor ninguém; 6- não há manual de instrução, nem de aplicação. Nesse sentido:

1- Para os alunos que jogam, esta pode e deve ser uma experiência divertida, mas para os professores não pode ser "brincadeira". O professor deve realizar os jogos com os objetivos bem delimitados para que a atividade realmente possa ser produtiva e proveitosa.

2- Os jogos propostos por este artigo são uma proposta metodológica e como tal, não podem ser usados como opção para os dias em que, por qualquer razão, a aula não tenha sido preparada.

3- Após o jogo o professor deve conduzir uma reflexão e uma discussão com os alunos para que se fixem os conceitos, para que eles possam dizer o que e como se sentiram, dúvidas, expectativas e sugestões para jogos posteriores.

4- Para que os jogos alcancem os efeitos desejados, não podem ser jogados uma única vez. Esta é uma atividade que exige disciplina. Para que seja realmente um jogo de qualidade deve ter frequência, funciona como processo, os resultados 
desejados serão apenas obtidos com a repetição e o envolvimento dos alunos o que ocorre apenas com o tempo.

5- É esperado que nas primeiras vezes nas quais os jogos forem realizados, os alunos não se sintam confortáveis e nem todos queiram participar. O professor não deve obrigá-los. Na medida em que eles se envolverem com os jogos estes receios tendem a diminuir e a participação e entrega a aumentar.

6- Não há manual de instrução, nem de aplicação, cada professor deve sentir seus alunos e fazer as adaptações necessárias aos jogos durante o processo, cada turma é única e também o processo o será.

\subsection{Vamos jogar?}

O jogo sugerido é o Jogo de argumentar.

Como jogar:

A classe é dividida em dois grupos. O professor deve determinar um tema para que os alunos possam desenvolver argumentos. O tema deve ser escrito na lousa que será dividida em duas partes uma destinada ao grupo 1 (a favor) e outra para o grupo 2 (contra). Cada grupo deverá eleger um representante para aquele dia. Quando o professor escrever o tema na lousa, os alunos devem ter 15 minutos para discutir e levantar argumentos que favoreçam as suas teses. Ao final deste tempo, cada representante deverá ir até a frente da sala e, após a realização do sorteio para determinar qual grupo irá começar, o primeiro representante inicia apresentando um argumento e o outro deverá responder com base no que foi discutido com o grupo, mas preocupando-se em rebater o argumento apresentado pelo outro jogador. O professor deve anotar todos os argumentos apresentados pelos jogadores, cada qual no lado destinado ao grupo na lousa. Ao final de 15 ou 20 minutos (dependerá de como está se desenvolvendo a atividade), o professor deverá encerrar esta parte do jogo.

Neste ponto, o jogo termina, mas a sequência didática não.

Aulas em que se pode jogar: redação e produção de texto.

Tempo total: uma aula. 
CAVALARI, A. L. F. Ensino de língua portuguesa...

\subsection{Sequência didática}

Este jogo foi pensado não apenas para abarcar as considerações tecidas por este artigo e inseri-las no contexto da sala de aula, mas, também, para trabalhar um aspecto fundamental à produção do texto dissertativo, a argumentação. Para tanto, faz-se necessário que, ao jogá-lo, os alunos tenham claro o que é um texto argumentativo, o que é uma dissertação e o que são argumentos. Quais os tipos que existem e como usá-los pode e deve ser ensinado durante a realização do jogo. Por isso, não restringirei uma idade ou um ciclo para este jogo, pode ser jogado em qualquer série, ciclo ou faixa etária em que o professor julgue ser necessário o trabalho com estes conceitos, visto que, a produção deste tipo de texto inicia-se no Ensino Fundamental II, mas estende-se até o final do Ensino Médio.

Inicialmente, sobretudo na primeira vez em que jogar, o professor deverá apresentar claramente as instruções e as regras do jogo.

Após a realização do jogo, inicia-se, então, a reflexão que deve contemplar uma breve discussão sobre como os alunos sentiram ao jogar, e, uma discussão relativa a apresentação dos argumentos utilizados por cada grupo, os tipos de argumentos, fracos ou fortes, classificação, outras possibilidades de argumentos, dependendo do que o professor acredite ser necessário àquela turma.

A sequência didática termina com a produção de um texto dissertativo por parte dos alunos, em casa, cada qual dependendo da posição de seu grupo, a favor ou contra o tema estabelecido. Os argumentos utilizados para a produção do texto devem ser os apresentados pelo grupo e seu representante, mas, o aluno deve acrescentar à sua redação ao menos um argumento novo não utilizado durante o jogo. As redações devem ser entregues ao professor na aula seguinte e podem servir para diagnóstico da eficiência do jogo e de quais aspectos concernentes ao uso dos argumentos podem ser melhor desenvolvidos nas próximas vezes em que os jogos forem aplicados.

Sugiro que o professor desenvolva esta sequência didática com regularidade de ao menos uma vez a cada mês, seis vezes no semestre, ou mais.

\section{Considerações finais}

Neste artigo, busquei apresentar os Jogos de Interação como uma possibilidade metodológica para o ensino de Língua Portuguesa no Ensino Fundamental II. Os Jogos, amplamente difundidos nas escolas e no meio teatral, são uma impor- 
tante contribuição para a vivência e a experiência com e por meio da linguagem. Foi, portanto, neles, e no teatro, que busquei inspiração para uma proposta pedagógica para o ensino de Língua Portuguesa que se baseia em dois princípios fundamentais; a linguagem como interação, como forma de ação e de aprender com e por meio do outro; e a vivência da linguagem para internalizá-la, apreendê-la, aprendê-la e experienciá-la.

Torna-se importante salientar que o que busquei propor neste artigo não é uma dinâmica de mecanização pura e simples da aplicação dos jogos nas aulas de Língua Portuguesa. Propus um caráter de experimentação para professores e alunos, a experimentação que é inerente ao jogo e deve perpassar o mero ensino da língua para ganhar a amplitude do ensino da linguagem.

\section{Referências}

BAKHTIN. M. Marxismo e filosofia da linguagem. Problemas fundamentais do método sociológico na ciência da linguagem. São Paulo: Hucitec, 1999. . Estética da criação verbal. São Paulo: Martins Fontes, 1992.

BARROS, D.L.P. Teoria do discurso. Fundamentos semióticos. São Paulo: Atual, 1988.

BENVENISTE. E. Problemas de Lingüística Geral I: Tradução de Maria da Glória Novak e Maria Luiza Neri: revisão do Prof. Isaac Nicolau Salum. 4. ed. Campinas: Pontes, 1995.

BOAL, A. Jogos para atores e não-atores. 10. ed. rer. e ampliada. Rio de Janeiro: Civilização Brasileira, 2007.

EMERSON, C. The Outer Word and Inner Speech: Bakhtin, Vygotsky, and the Internalization of Language. Critical Inquiry, v. 10, n. 2 (dec., 1983), p. 245-264. Published by: The University of Chicago Press Stable URL: http://www.jstor.org/ stable/1343349.

JAPIASSU, R. O. V. Metodologia do ensino do teatro. 8.ed. Campinas: Papirus, 2009.

JOHNSON. M. Mind incarnate: from Dewey to Damasio. The American Academy of Arts\& Sciences. Daedalus Summer: 2006. 
CAVALARI, A. L. F. Ensino de língua portuguesa...

LURIA, A. R. Curso de Psicologia Geral. Volume I. Introdução Evolucionista à Psicologia. Rio de Janeiro: Civilização brasileira, 1991.

REVERBEL, O. Jogos teatrais na escola: atividades globais de expressão. São Paulo: Scipione, 2007.

RYNGAERT, J. P. Jogar, representar: práticas dramáticas e formação. Trad. Cássia Raquel da Silveira. São Paulo: Cosac Naify, 2009.

SARTINGEN, K. Brecht no teatro brasileiro. Trad. José Pedro Antunes. São Paulo: Hucetec, 1998.

SMOLKA, A. L. Cadernos Cedes 24 - Pensamento e linguagem. Estudos na perspectiva da psicologia soviética. Campinas: Papirus, 1991.

SPOLIN, V. Jogos teatrais na sala de aula: um manual para o professor. 2.ed.Trad. VYGOTSKY, L.S. A formação social da mente. O desenvolvimento dos processos psicológicos superiores. São Paulo: Martins Fontes, 2003.

Abstract: This article presents Interaction Games as a methodological choice for Portuguese language teaching in Elementary School II. The games, widely in the theatre field, contribute in a very important way to the experience and undergo with the language and through it. The theoretical fundamentation is centered on Psychology, Linguistics, Theater Pedagogy, especially on the perspective interactional language as constituting subjects and on the non-dualistic view of the body and mind.

Keywords: portuguese language teaching; interaction; Linguistics; games. 